\title{
Regulation of Lifelong in Education and İts Economic, Social Benefits
}

\author{
Allahyar Muradov ${ }^{1}$ Rasmiyya Abdullayeva², Azad Musayev³, Akbar Abbasov ${ }^{4}$, Sabina \\ Abbasova ${ }^{5}$ \\ ${ }^{1} \mathrm{PhD}$ in Econ., Assoc.Prof. Azerbaijan National Academy of Science, Institute of Economics \\ E-mail: allahyarmurad@gmail.com \\ ${ }^{2} \mathrm{PhD}$ in Econ., Assoc.Prof. Azerbaijan National Academy of Science, Institute of Economics \\ E-mail: resmiyyesabir@gmail.com \\ ${ }^{3}$ Doctorate, Azerbaijan National Academy of Science, Institute of Economics \\ E-mail: azad1985@gmail.com \\ ${ }^{4}$ Doctorate, Azerbaijan National Academy of Science, Institute of Economics \\ E-mail: akbar.abbasov@gmail.com \\ ${ }^{5}$ Doctorate, Azerbaijan National Academy of Science, Institute of Economics \\ E-mail: sabinaheydar@gmail.com
}

Article History: Received: 10 November 2020; Revised 12 January 2021; Accepted: 27 January 2021; Published online: 5 April 2021

\begin{abstract}
Sustainability in education is important in ensuring knowledge-based and innovation-driven development and human capital reproduction. Sustainability is particular important for the prevention of some economic and social problems that may arise in the future and raising the competitiveness of the country. Sustainability - the prevention as some of economic and social problems that may arise in the future is of particular importance in raising the country's competitiveness.

The aim of the research is to estimate the economic-social benefits of regulation of sustainability in education and to give the suggestions in the direction of the improvement of the effectiveness of the regulation.

The impact of continuity in education on the formation and development of human capital, knowledge-based society building, labour intelligence, competitiveness and the improvement of welfare are assessed cross-country in the article. In particular, in recent years, researches and politicians have analysed the '4th industry' revolution ('Industry 4.0') 'the benefits and losses in the medium and long-term perspective and its interaction with the sustainability of education. Here are two issues: 1) socioeconomic disadvantages of ensuring sustainability in education, 2) socioeconomic advantages of ensuring sustainability in education. Firstly, it is analysed the impacts of increased unemployment, reduction of employment income, declining social security and welfare that will be resulted as problems on economic development. Secondly, it is analysed (ensuring in sustainability condition) the distinguished factors of rapid technological innovation, labour productivity, repatriation of human capital, raising competitiveness on the international level, innovation-based development, economic benefits of knowledge and skills.
\end{abstract}

Keywords: Education, Knowledge, Innovation, Information, Regulation.

\section{Introduction}

As a result of rapid technical and technological innovation in recent years, labour-intensive jobs have been replaced by jobs with intellect (knowledge) sparing. This process requires the 
initiation of a more effective regulatory mechanism for the forming and reproduction of human capital. Reproduction of human capital can be equal to the sustainability of education, because of recreation happens when the human capital is available to update itself with on the background of continuous training and education. The development dynamics of science and the economy show that it is impossible to increase the country's (company's) competitive power in the medium and long term without forming human capital in accordance with the fast-changing demands of the labour market. Thus, the 'Industry 4.0' revolution reveals the sustainability of education (training) as well as the implementation of more flexible policy in this direction compared to previous periods.

Obviously, as a result of the development of science and economy, a great number of new professions and specialties have so far been created and will continue to be new. This will increase the demand for better qualitative workforce by changing the structure of the economy and the labour market. Therefore, in order to benefit from the advantages of 'Industry 4.0' and to prevent its problems that may arise (especially in developing and weakly developed countries), there should be no delay in reforming scientific activity, education and training. I think that, delay in this process can lead to serious economic and social problems in the medium and long term. At present, a number of brain centres in the world (McKinsey, WB, WEF, EY, WIPO, UNESCO, The Economist) are focusing on Industry 4.0 and the problem of sustainability of education. According to calculations, as a result of rapid technical and technological renovation, about $70 \%$ of their locations will be fully or partially automated in the next five years. This will result in the reduction of jobs on the one hand and, on the other hand, the creation of new jobs. The demand will be increase for higher qualitative human capital, professions and specialties in the new work places. This at the same time will have an impact on the deepen increase the tension in the labour market (the rising gap between the knowledge required and the proposed knowledge). Another point that is remarkable is the process of demographic aging (an increase in the number of the elderly people) in the world (especially in developed and developing countries).

In addition to new professions and specialties, the demographic aging process can also create difficulties in the social protection system. Thereby, on the one hand, the increase in the specific weight of the elderly in labour resources and on the other hand, the weakness of their ability to apply modern technologies and of course, the dim learning potential (compared to young people) of these people require significant changes in the education and training technology. Research by the McKinsey Global Institute shows that there are only 285 million elderly people in the together of the United States and 15 EU countries and 100 million of them want to work. (McKinsey Global Institute, 2017)

Researchers have suggested that the demographic aging process can create problems in the social security system (Czaja \& Lee 2007, Abdullayeva, Hashimova, 2017). Knowledge acquired as a result of technical and technological renewal, job, professions and specialties will raise the issue of sustainability in education (training). All of this require a change in the demand the period of time in education, innovation, labour market and social policy through 'flexible intervention' and 'incentive mechanisms.' In a such period, it is desirable to find out the increase of effectiveness in the economic and social field and in the proving of the 
sustainability of reproduction of the human capital (training and education) as taking advantage of 'Industry 4.0' revolution's economic preferences.

Strategy of the sustainability in education (lifelong study) is not the recent years of idea. This idea has been become urgent during the "Industry 3.0" (UNESCO, 1972) stage. At that time, the problem of scientific-technical (technological) growth was weaker than the modern one, so the problem has not been the focus of attention as today. The main reason is the acceleration of technical and technological update, the knowledge and innovation's turning into a leading force in the economy, the automation of hand labour, the rapidness of upcoming knowledge and professions and etc. Generally, education (training) create base for the reproduction of human capital 'flexibility' and increasing effectiveness of using them. At this stage, such a policy should be followed so that economic growth does not deepen social problems.

Kovacs (Kovacs, 2018) rightly believes that the sustainability of 'Industry 4.0' and 'Digital Economy' can only be achieved through comprehensive economic growth and strong social security that guarantees political stability. Directly as the words of Kovacs - "The sustained development of Industry 4.0 and Digital Economy can only be cultivated via inclusive growth that safeguards political stability through strengthened social trust". The solution of the problem is to strive to 'flexibility' and efficiency in the reproduction of human capital (lifelong learning). The human factor stands on even the most sophisticated and complicated technology. Through, it is the person who creates, uses and upgrade technology.

\section{Literature Review}

Education generally enacts a key role in the socioeconomic development of the country. Since, education meets needs of people as gaining defined professions and qualifications with a way of moral and intellectual development. (Muradov 2006) In the knowledge-based economy, the demand for education and highly intelligent people has grown up exceptionally. Consistently complicated and updated technologies and equipment, innovative production processes, respectively require intellectual employees. Consequently, the fact that sustainable and quality education in the formation of the knowledge-based economy is extremely important in contemporary society and its political, economic, social, cultural development and due to this, it is one of the generally accepted and non-controversy issues (Muradov, 2017, p 150).

Modern technological advancements are not just about radical changes in science, technology and the structure of the economy, but also in the change of people's lifestyle, outlook. So, modern technology has become an important 'component' of people's lifestyle and economic development. This tendency turns into the inevitable factor of human capital development (It is essential to keep in focus quality of education), intellectual labour and its increasing productivity. Certainly, it is not excluded that 'Industry 4.0' generates specific problems in the society and economy. Researchers (Ancarani, Mauro \& Mascali, 2019; Frank, Dalenogare $\&$ Ayala, 2019) and politicians also make different assessments of the benefits and losses of the "Industry 4.0 " in the perspective of the medium and long term.

There is no doubt, it is indisputable fact of the economic and social advantages of the technological revolution. Unlike economic advantages, controversial ideas are put forward as 
we have mentioned in terms of social preferences. However, economic benefits and social impacts of technological innovation will not be the same in all countries as our opinion. Whereas the self-regulation potential of the nations is different (Muzaffarli, 2014) and here the potential for adaptation to the changes in society and the implemented policy of 'assimilation' capability plays a crucial role. For example, McKinsey's Paris office in 2011 found that the Internet had resulted in a reduction of 500,000 jobs in France and occurred 1.2 million new jobs. (McKinsey Global Institute, 2017) Each new job requires the adoption of a new profession and qualifications that enhances the importance of sustainable education.

Influence of technological innovation on social security system (Stavnycha \& Jasińska, 2018), progress of innovation potential (Muradov \& Huseynov, 2013; Babayev \& Hajiyev, 2019).), impact on employment and labour market (WEF, 2016; Harnad, 1991; Silva \& Lima, 2017; Odyegov \& Pavlova, 2019; Heinrich, 2019) and etc. such as economic and social impacts have been explored in many aspects. All the studies have roughly shown the development of the education system as well as the provision of sustainability of education as a key solution to the problem. It means sustainability of education (especially for those who aged 15-65) at all stages of society is of strategic importance.

Lifelong learning (Korshunov, Gaponova, 2017; Aleandri and Refrigeri, 2013), creating favourable conditions for increasing the knowledge and skills of the workforce have a major importance. In recent years, a sharp growth trend in the direction of Artificial intelligence, Machine Learning, Robotic Process Automation or RPA, Block chain, Edge Computing, Virtual Reality and Augmented Reality, Cyber Security, Internet of Things and so on tend to increase the importance of 'flexibility' in the sustainability of education (training) and seriously changes the structure of the economy and employment. Let's pay attention some of the fastest growing AI based (Artificial Intelligence) indicators in last years. "Artificial Intelligence" that first appeared in the 50s of the last centuries and related with it 340,000 inventions have been made, more than 1.6 million scientific works have been published (WIPO, 2019, p.13). At present, the US and People's Republic of China are leading in the global AI market. About $41 \%$ of global investment in AI belongs to San Francisco (USA). The number of start-ups in this track is increasing. The number of active AI Start-up in the United States has been merely increased by 13\% in 2018 compared to 2015 (WIPO, 2019 p.31). During this period VC (Venture Capital) volume increased by $350 \%$ in AI (AI Index 2018 , p.31). Europe ranks second place in the AI market and predicts to invest 24.4 billion in this field by 2020. China plans to establish AI industry worth 150 billion by 2030(EY, 2019). In recent years, the rate of the robotization in the industry has increased in the world, especially in China. Compared to 2012, an average number of robotized machines in China in 2017 increased by of 500\% a year, 105\% in South Korea and 122\% in Japan.

Experts estimate by the end of 2030; 73 million jobs will be lost in Europe as a result of automation. However, new jobs will also be born together with losing of them. It is believed that the difference between diminished jobs and emerging created ones in the short and midterm perspective will be great in countries with exactly low level of technological readiness. According to expert analysis, 23 million AI based jobs will be set up in 2020 (Industry 4.0, p.14). According to the calculations of "McKinsey" that jobs in the workplace are fully 
automated by 5\% and partially automated by $60 \%$ (McKinsey Global Institute, 2017). All of this proves that sustainability in education is more flexible compared to previous years and clarifies a decisive role in the implementation of the medium and long-term strategy of countries.

\section{Methodology}

In this study, 79 countries and 25 indicators were selected that their statistics available to evaluate the social and economic benefits of the lifetime learning period. These indicators are divided into two blocks, that 13 indicators for evaluating social benefits, 12 indicators to assess economic benefits. It is believed that they are important for re-capitalization and economic development of human capital in our opinion. The study also IA taken into account the expectations of the "Industry 4.0 " revolution. In the study, correlations were sought between 25 indicators using the Excel program. (Table1)

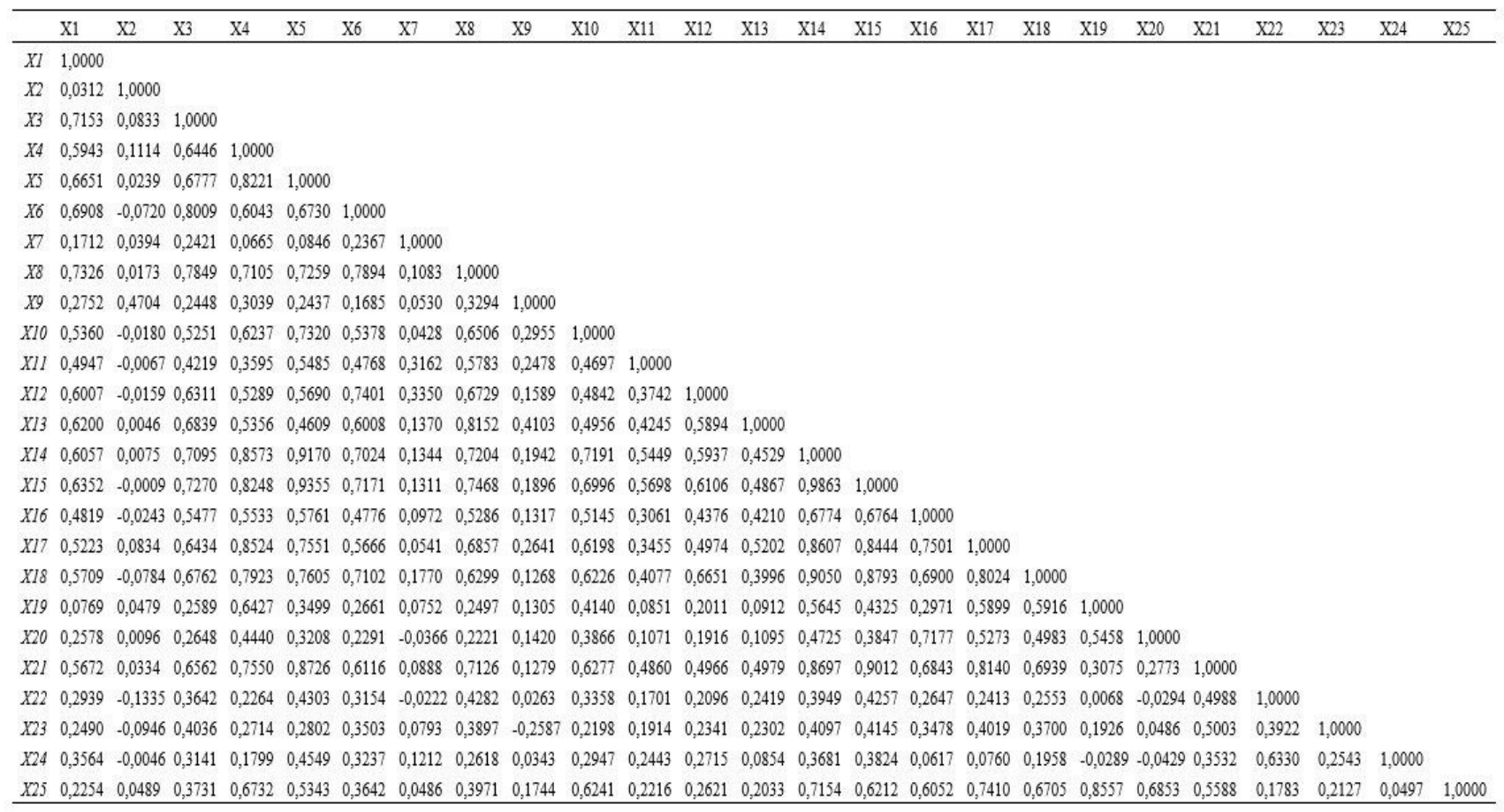

Source: https://databank.worldbank.org/indicator/NY.GDP.MKTP.KD.ZG/1ff4a498/PopularIndicators.

Social indicators: $X_{1}$-Expected years of schooling; $X_{2}$-Compulsory education, (years); $X_{3^{-}}$ Life expectancy at birth, total (years); $X_{4}$ - costs per employee, salary including to expenses (annual); $X_{5}$-Government expenditure on education, per capita; $X_{6}$ - Individuals using the Internet (\% of population); $X_{7-}$ Mobile cellular subscriptions (per 100 people); $X_{8}$ Fixed broadband subscriptions (per 100 people); $X_{9}$ - Labour force with advanced education

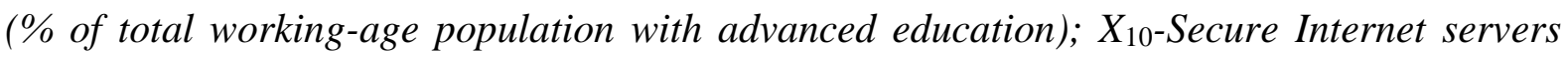
(per 1 million people); $X_{11}$-Labor force participation rate, total (\% of total population ages 15-64) (modelled ILO estimate); $X_{12}$-Wage and salaried workers, total (\% of total 
employment) (modelled ILO estimate); $X_{13}$-Age dependency ratio, old (\% of working-age population);

Economic indicators: $X_{14-G D P}$ per capita (current ); $X_{15-G N I}$ per capita, Atlas method

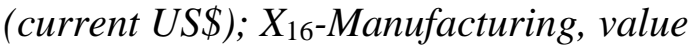

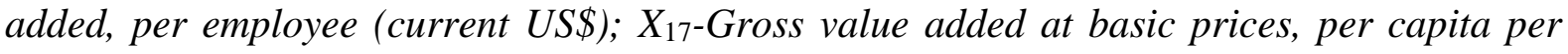
employee (current US\$); $X_{18}-$ GDP per capita employed (constant 2011 PPP \$); $X_{19}$ Commercial service exports, per labour force, (current US\$) per Labour total; $X_{20}-I C T$ service exports per labour force (Bop, current US\$); $X_{21}$-Research and development expenditure, per capita; $X_{22}$-Industrial design applications, resident and non-resident, by count per 10000 employee $X_{23}$-Patent applications, residents and non-residents per 100000 capita; $X_{24}$-Trademark applications, total per 10000employee; $X_{25}$-Charges for the use of intellectual property, receipts (Bop, current US\$)

\section{Mutual relationships between expected duration of education and social indicators}

Industry 4.0 will accelerate the socio-economic progress of the countries by boosting up the reproduction process of human resources (educational sustainability). That in the 21st century, where the labour market is rapidly becoming intellectual, it is impossible to make a profit without capitalizing on human assets. It is observed in analysis that, there is a growing demand for enriched human capital in the labour market and the parallel ongoing rise in the expected duration of the educational process, as well as the increase in dependence on technical, technological innovations (Industry-4.0) and socioeconomic indicators. Occasionally, there are ideas about technological development and automation that will increase unemployment. It is expected in the medium and long term periods. Despite of that fact, the stratigraphic analysis of 2010-2017 shows that the unemployment rate has dropped dramatically down in some developed and developing economies, although friction of technical and technological development. The number of unemployed has dropped to in Germany - 3.54\%, United Kingdom - 3.83\%, Sweden -2.17\%, Ireland -8.84\%, Japan-2.65, World $-0.52 \%$. (World Bank Group, 2019).

It dictates that technological advancement has not yet increased the level of unemployment, but rather reduced it. There is pretty growth in the expected duration of education in selected countries and in our opinion, it is directly related with the reproduction of human capital and the rational use of this capital in the labour market. This tendency is clearly understandable when looking at the dynamics of value added for per person employed. In the majority of the world, there is a growing dynamic in the value added for per person employed. The following diagram proves in the 28 developed and developing countries in 2010-2017, an increase in value added for per person employed in GDP (constant 2011 PPP \$). There has been a sharp decline in Azerbaijan and Hungary.

In the analysed countries, the expected duration of education has got on, for example, in Australia 17.4 to 22.9, in Belgium 14.1 to 19.8, in Israel 12.1 to 19.6, in Sweden 12.9 to 17.6. Unless the other indicators are taken into consideration, it makes urgent the sustainability of human capital reproduction in modern age that technological innovation is accelerating and 
expected period of education has increased. Otherwise, serious problems can be arisen in the field of economic and social wellbeing.

Sustainability of education also occurs in the labour process, along with educational and training institutions. There are a number of intellect weighted fields that are directly involved in ensuring the sustainability of education and some indirectly. In fact, intellect weighted fields and those employed in are involved actually in lifelong learning, practice, and professionalism. Therefore, the development of areas requiring intellectual labour creates great opportunities for sustainability of education.

Correlation dependence $(\mathrm{r}=0.0312)$ between the expected duration of education and compulsory education $\left(\mathrm{X}_{1}\right.$ and $\left.\mathrm{X}_{2}\right)$ is low. (Figure 1) Compulsory education in countries around the world ranges from 5 to 16 years (most countries over 12 years are economically deprived, even in some countries the expected learning time is less than compulsory). This means that the length of compulsory education is not so important for socio-economic development. In our opinion, it is important to encourage people to get education as voluntarily. In other words, a system should be established between education and the labour market so that people should presume education as a guarantee of their future life. In this regard, the state should develop stimulating and incentive mechanisms. People should choose the profession and specialty they need freely, and it should be created a favourable environment for its market implementation.

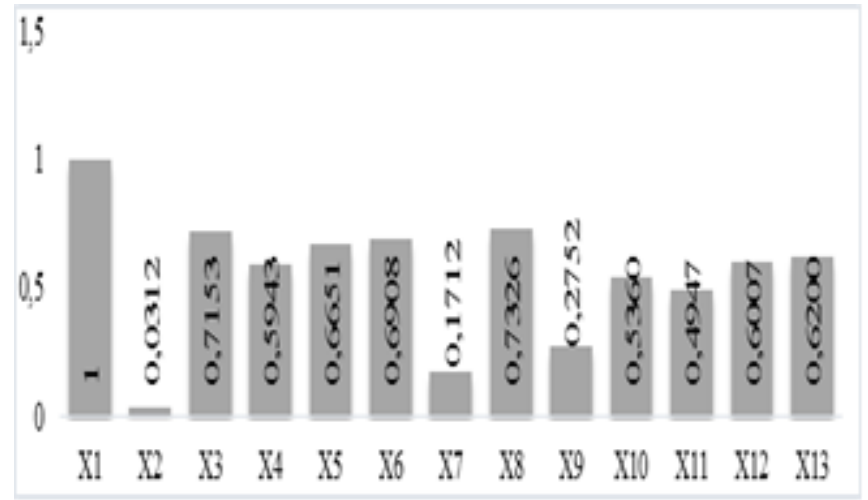

Figure 1. Correlation expected years of schooling and social indicators

Source:https://databank.worldbank.org/indicator/NY.GDP.MKTP.KD.ZG/1ff4a498/PopularIndicators. 21.07.2019

The assessment was conducted on the basis of indicators of the World Bank in 2017, among 79 countries.

There is a high correlation relationship (0.7153) between life expectancy at birth and expected lifelong education. It is possible to explain that, if a person spends most of his life to education (voluntarily) is healthier and long-lived or vice versa. In our view, length of the life of people are bounded to the knowledge they gained and its realization is connected to environment, lifestyle and confidence to the future. Trust to the future affects the growth of life expectancy by creating positive energy. Moreover, in modern age, high level of knowledge and professionalism is an important condition for improving the well-being of 
people. The wage of the labour force included in this category is higher, stimulating and allowing them to steady increase their health conditions and education. Psychological factor should also be carefully considered.

People with low educational background or professionalism level have poor job opportunities, (especially in Industry-3.0 and Industry-4.0) and high risk of job loss due to that by a negative impact on their psychological state, their life length is got shorten. Political tensions, social injustice, and so on as well as factors preventing the sustainability of education. However, this may be the subject of another research.

One of the social situations where correlation is high is between the fixed broadband subscriptions (per 100 capita) $\left(\mathrm{X}_{1}\right.$ and $\left.\mathrm{X}_{8}=0.7326\right)$ and an expected lifetime of education. Modern ICT systems and access to the global Internet networks have a positive impact on the increase of the duration of lifelong education. At present, distance education in the world, various training programs and the relevance of training information should be regarded as a positive factor in the sustainability of education. In the ICT Development Index, countries with the high level of the expectation of lifetime education is among the top priorities. (ITU, 2017)

There is a poor correlation between mobile cellular subscriptions and labour force with advanced education and the expected lifetime of education. However, the essence consists of per communication tool for mobile communication. It should be borne in mind that modern mobile phones are also "walking internet" and the vast majority of people get access to the internet through mobile phones. There are middle class of correlated relationships among the government expenditure on education, individuals using the internet ( $\%$ of population), wage and salaried workers and age dependency. Government education expenditures per capita, the number of internet users, and the salaries of the workers in the labour market have a positive impact on the increase of expected lifetime of education. All of these are important in terms of the development of society and in addition to increasing the social benefits of education, it also gives benefits as economic advantages with raising competitiveness (individuals and states). Thus, by reducing the duration of compulsory education, it is possible to increase lifetime education duration and its social, economic benefits. For example, the reduction of 16 years of compulsory education to 8 years can be raised government education expenditures (in many cases, the quality of compulsory education is low), and the ability to gain contemporary knowledge in a rapidly changing period. In contrast to previous years, the loss of time in knowledge acquisition and use can result in "economic loss" that ultimately can undermine the social benefits of education.

\section{Interaction between expected lifetime education and economic indicators}

Increased duration of expected education (unlike compulsory education) has gains for the development of country and individuals. Especially in the condition of Industry-4.0 revolution, the availability of opportunities to increase knowledge and skills of people in accordance with the changing labour market requirements and the flexible, effective state regulation policy can be more useful for economic growth. The flexible regulatory policy in the education and labour market allows the labour force to increase or change their 
qualifications volunteer. There is a positive correlation science increased of expected sustainability of education in GDP $\left(\mathrm{X}_{14^{-}}\right)(\mathrm{r}=0.6057)$ per capita GNP $\left(\mathrm{X}_{15^{-}}\right)\left(\mathrm{X}_{14^{-}} \mathrm{r}=\right.$ $0.6352)$ per capita, GDP $\left(\mathrm{X}_{18^{-}}\right)(\mathrm{r}=0.5709)$ per employee, financing science $\left(\mathrm{X}_{21}\right)(\mathrm{r}=$ 0.5672). (Figure 2)

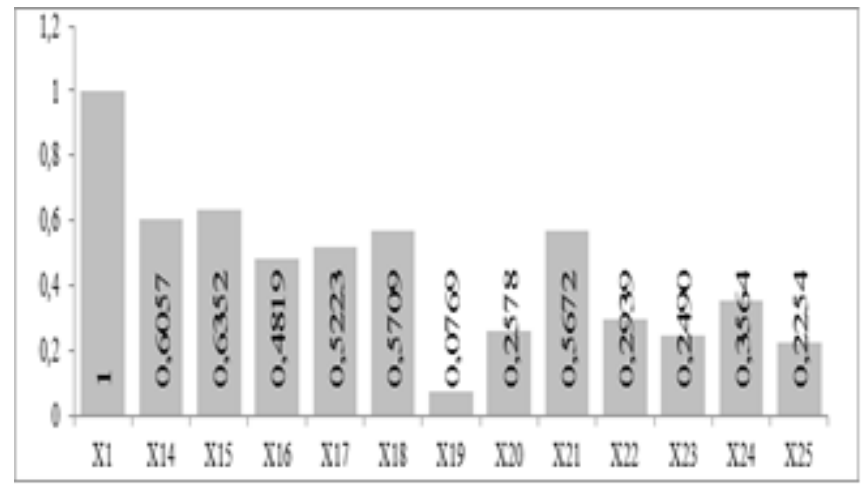

Figure 2. Correlation expected years of schooling (years)

Source:

https://databank.worldbank.org/indicator /NY.GDP.MKTP.KD.ZG/1ff4a498/Popular-Indicators 21.07.2019

The incentive system created in the research and development area accelerates the reproduction of human capital in developed countries. Science is one of the few fields where the sustainability of learning realized. We can also assess these countries as the efficiency of human capital use. Thus, the main component of the national wealth is human capital and the amount of human capital in the national wealth increases regularly. While education increases income, directly multiplied income leads to a healthier lifestyle, longer life and more benefit to the economy of country. Putting the issue in this direction is useful for achieving the goal set by Inustry-4.0.

The indexes of sustainability of education expectancy at the Global Innovation Index (GPO, 2017) are high in the top ten countries (other indicators are for 2017, as the GDI 2017 indicators have been used), Switzerland (17.6 years), Sweden (17.6 years), Netherlands (18 years), United States (16.5), United Kingdom (17.4), Denmark (19.1 years), Singapore (16.2 years), Finland (17.6 years), Germany (17.0 years). Global Competitiveness Index (GCI, 2017-2018) first ranked countries: Switzerland 5.9, United States, Singapore 5.7, Netherlands 5.7, Germany 5.7, Hong Kong SAR 5.5 Sweden, 5.5, United Kingdom, 5.5, Japan 5.5, Finland 5.5, Norway 5.4, Denmark 5.4, has also seen the names of the countries that are in the first place in the RIA. This gives clear path that the sustainability of education expectancy is dependent on innovation and competitive economic growth.

The research has indicated that sustainability of education in the 21 st century is crucial as the rapid development of automation, digitalization and artificial intelligence technologies. Particularly, it stands for the basic conditions of innovative and competitive economy establishment. It interprets that the readiness of countries for automation, digitization, artificial intelligence technology rests just sustainability of education and the process of reproduction of human capital. 
The Economist Intelligence Unit has assessed the level of readiness to automation for 25 countries based on 28 indicators (over 100 points) covering the labour market, education policy and innovation environment. Based on the The Automation Readiness Index first ten countries that ranked in top South Korea (91.3), Germany (89.6) Singapore (87.5), Japan (83.7), Canada (82.6), Estonia (80.0), France (79.2), United Kingdom (75.6), United States (72.8), Australia (71.5). (ARI, 2019) The following charts illustrate the relationship between education policy, labour market, innovation environment and labour market policy.

Figure 3. Innovation environment, Educatiom Policies and Labour Market Policies

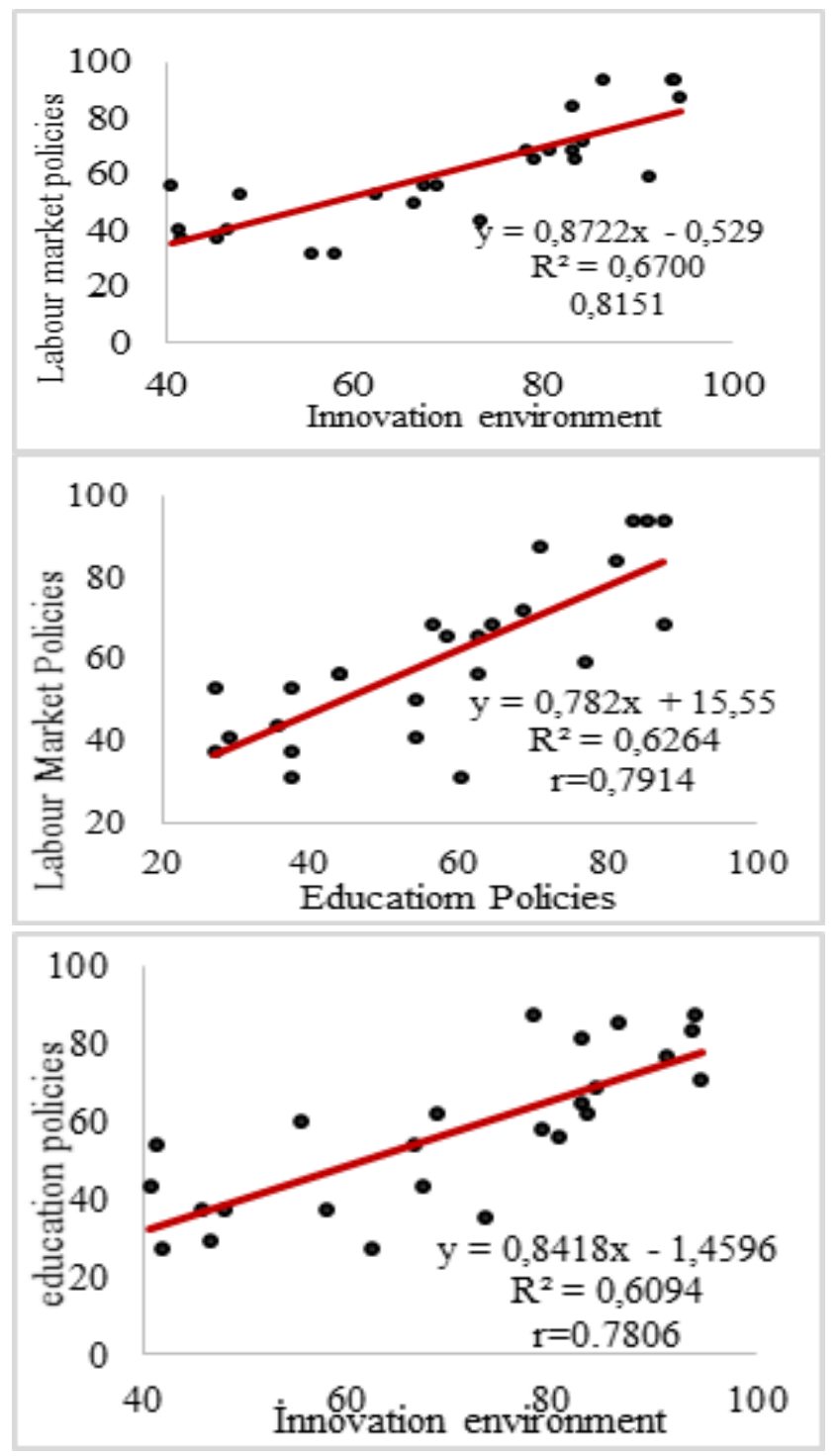

Source: The Automation Readiness Index 2019

The development of innovation products requires competition in the market, increasing flexibility in education and training in the labor market as well as effective state regulation in this fields. Especially in the Industry-4.0 environment special attention to startups and acceleration of artificial intelligence, automation, robotization, digitalization and etcetera are noticeable. In fact, along with other intellectual activities, startups are also important in terms of sustainability of education. The increased attention to Start-ups and the socio-economic benefits of it, make the number of researches in this context grow. CEO World Magazine 
makes "Most Startup Friendly" Index based on 5 subindices, based on Human Capital Investment, Research \& Development, Entrepreneurial Infrastructure, Technical Workforce and Policy Dynamics subindices. Countries in the top ten rankings in this index are also similar to the countries in the HDI and the GRI index (with some exception).

Today there should be a co-ordination between "science-education-industry" that encourages the innovative development of country, people for gaining new knowledge and creating special centers for the acquisition of new knowledge. The effectiveness of the regulation of this process will depend on the degree of its encouragement, stimulation and support rather than administrative methods.

\section{Result}

Our main finding in this study is to discover that the duration of compulsory education effects weakly to the social and economic indicators. In recent years, countries have tried to increase duration of compulsory educational. The long period of compulsory education may also be assessed as time loss. This policy must be changed, compulsory education period should be reduced (end of compulsory education by the age of 15), flexible education and training system should be established in accordance with the rapidly changing labor market. Modern people prefer not compulsion, but volunteering.

Research proposes that business environment should be favorable for ensuring sustainability of education and increasing socio-economic benefits and promoting science development, identifying priorities for production and service, so supporting the development of field requiring intellectual labor. In order to have a positive effect on the well-being of the country and its international reputation, sustainability of education and reproduction of human capital must be provided.

\section{References}

[1] Abdullayeva, R., Hashimova, V. (2017) The liberal-administrative level and socioeconomic development of the pension system. IS (S) I-2015. The potential of liberalism in the economy. p.136-159

[2] AI Index 2018 Report. 2018 by Stanford University

[3] Aleandri, G. and Refrigeri, L. (2013) Lifelong learning, training and education in globalized economic systems: G. Analysis and Perspectives / Procedia - Social and Behavioral Sciences 93 (2013) $1242-1248$

[4] Ancarani, A., Mauro, C.D., Mascali, F. (2019) Backshoring strategy and the adoption of Industry 4.0: Evidence from Europe, Journal of World Business, Volume 54, Issue 4, 2019, Pages 360-371

[5] Babayev, B., Hajiyev, N. (2019). Building an innovation ecosystem in Azerbaijan - on the basis of the study of israeli practice._37th International Scientific Conference on Economic and Social Development - Socio Economic Problems of Sustainable Development. Baku, AZERBAIJAN, 2019, p 312-319

[6] Blossfeld, H.P., \& Jutta, M. (2019). Education as a Lifelong Process. 10.1007/978-3-65823162-0_2.

[7] Czaja, SJ., Lee C.C (2007) The impact of aging on access to technology ACM SIGACCESS Accessibility and Computing 5(4): 341-349 March 2007. DOI: 10.1145/1102187.1102189 
[8] Duggal, N. (2019) 8 Top Technology Trends for 2019 and the Jobs They'll

[9] EY-Mint Emerging Technologies Report (2019) Emerging Technologies: Changing how we live, work and play 2019

[10] Frank, A.G., Dalenogare, LS., Ayala, N.F (2019) Industry 4.0 technologies: implementation patterns in manufacturing companies, International Journal of Production Economics (2019).

[11] GCI, (2017-2018) The Global Competitiveness Report 2017-2018.

[12] Giİ, (2017) Global Innovation Index 2017

[13] Harnad, S. (1991) Post-Gutenberg galaxy: The fourth revolution in the means of production of knowledge. Public-access computer systems review 2.1 (1991): 39-53.

[14] Heinrich, M. (2019) Industry 4.0: How it will affect employment and what skills will be required to match the requirements of the market, April 2018

[15] Industry 4.0. (2015) A Discussion of Qualifications and Skills in the Factory of the Future.

[16] ITU, (2017) Measuring the Information Society Report 2017 Volume 1, International Telecommunication Union Place des Nations, Switzerland

[17] Korshunov, I., Gaponova, O. (2017) Lifelong Learning in the Context of Economic Development and Government Effectiveness. Voprosy obrazovaniya / Educational Studies Moscow. 2017. No 4. P. 36-59

[18] Kovacs, O. (2018), The dark corners of industry 4.0 - Grounding economic governance 2.0. Technology in Society (2018), McKinsey Global Institute (2017) Technology, jobs, and the future of work. May 2017

[19] Muradov A. (2017) Building knowledge economy: opportunities for liberal and conductor models. IS (S) I - 2015: Economic potential of liberalism (with Nazim Muzaffarli's scientific editorial note) p. 106-138

[20] Muradov, A., Hasanli, Y., Musayeva, F. (2019) Estimation Of The Education Influence On The Population Income. Economic and Social Development (ESD 2019): 37th International Scientific Conference on Economic and Social Development - Socio Economic Problems of Sustainable Development. P 593-602

[21] Muradov, A., Huseynov, R. (2013) Peculiarities of economic development on the basis of innovation and innovation potential. Conference: Technology Transfer and Innovations, 2nd Annual Conference \& Networking, October 29-30, 2013,

[22] Muzaffarli (İmanov), N. (2014) The social dimension of the economy in right and left systems. Baku, East-West Publishing House, 2014, 272 p.

[23] Odyegov Y. G., Pavlova V. V. (2019) The Transformation of Work: Sixth Technological Way, Digital Economy and Trends in Changing Employment // Level of Life of the Population of Regions of Russia. 2019. no. pp. 30-41.

[24] Rizvi, S., Rienties, B., Khoja, SA (2019) The role of demographics in online learning; A decision tree based approach. V 137, p. 32-47

[25] Silva, HC., Lima, F. (2017) Technology, employment and skills: A look into job duration/ Research Policy Volume 46, Issue 8, October 2017, Pages 1519-1530

[26] Stavnycha, N., Jasińska J. (2018) Fourth industrial revolution and its influence on social security of the state. World Scientific News 104 (2018) 34-44.

[27] The Automation Readiness Index: Who is ready for the coming wave of automation? is an Economist Intelligence Unit report, commissioned by ABB.

[28] The World Bank Group https://data.worldbank.org/indicator/SL.UEM.TOTL.ZS?view=chart

[29] UNESCO (1972) Edgar Faure, Learning to be: The world of education today and tomorrow. 
[30] WEF (2016) Global Challenge Insight Report. The Future of Jobs. Employment, Skills and Workforce Strategy for the Fourth Industrial Revolution/ Global Challenge Insight Report, January 2016

[31] WEF-2018. The Future of Jobs Report 2018,

[32] WIPO (2019) Technology Trends 2019. Artificial Intelligence. 